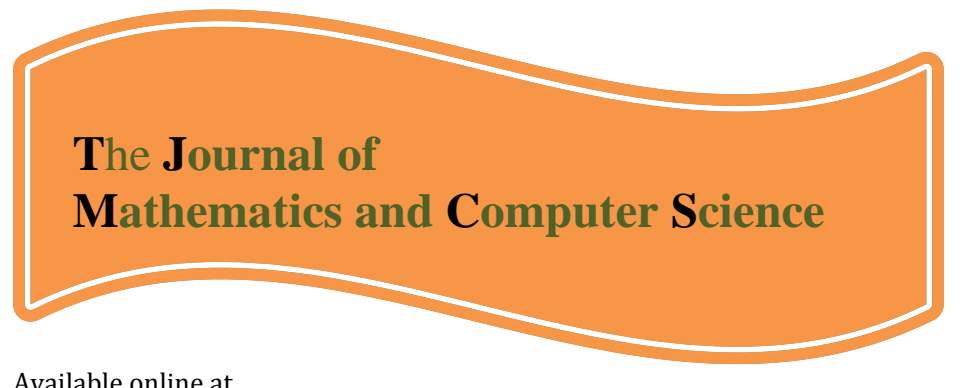

Available online at

http://www.TJMCS.com

The Journal of Mathematics and Computer Science Vol .2 No.2 (2011) 311-318

\title{
Vendor Performance Measurement Using Fuzzy Logic Controller
}

\author{
Hadi Shirouyehzad ${ }^{1,}$, Hamidreza Panjehfouladgaran'2, Reza Dabestani' ${ }^{3}$, Mostafa Badakhshian ${ }^{4}$, \\ Faculty Member of IE Department Islamic Azad University, Najafabad Branch, hadi.shirouyehzad@gmail.com \\ MSc. of Industrial and system engineering, hamidfouladgaran@gmail.com \\ Management department, Isfahan University, reza.dabestani@gmail.com \\ R\&D Department, Deputy of Transportation and Traffic, Municipality of Isfahan, m.badakhshian@gmail.com
}

Received: September 2010, Revised: November 2010

Online Publication: January 2011

\begin{abstract}
The era of globalization has begun and organizations endeavor to increase their market share in the competitive environment. To achieve the mentioned goal, organizations should increase their effectiveness as a major strategy in order to improve their performance. Performance measurement as a managerial key can be used for monitoring activities in organizations. Vendors' selection is one of the issues which influence the efficiency of organizations. Therefore, performance measurement of vendors plays a vital role in firms. Many conceptual and analytical models have been developed for addressing vendor selection problems. Hence, a suitable approach is needed to consider all the factors in order to select the most efficient vendor. In this paper, fuzzy logic controller as a robust and easy understanding approach is applied to transform the quantitative variable to linguistic terms in order to measure the vendors' performance. Four criteria which can influence vendors' performance are considered. The criteria are service quality, price, lateness deliveries and rate of rejected parts.
\end{abstract}

Keywords: Vendor Selection, Performance Measurement, Fuzzy Logic Controller (FLC).

\footnotetext{
1, Faculty member

${ }^{2}$, Corresponding author: MSc. of Industrial and Systems Engineering

3, MSc. candidate, Industrial Management

${ }^{4,}$ MSc. of Industrial and Systems Engineering
} 


\section{Introduction}

Supply chain management (SCM) is a process which tries to fulfill the customers' request. SCM consist of suppliers, manufacturers, distributors, retailers and customers which product flow from downstream to upstream and information flows in both directions [1], [2]. Improving efficiency and effectiveness as the most valuable factors from the customers' point of view are one of the major goals of SCM [3]. To achieve the mentioned goal, organizations should concentrate on improving their activities in order to increase their competitive advantages in the whole supply chain rather than the single firm. One of the crucial decision making problems in SCM is vendor selection which may influence organizations' performance directly. Therefore, selecting the most suitable vendor at the right time by predetermined quota of allocation is one of the managers' challenges [4].

There must be an ongoing process to define the procurement requirement needed to support the company's business plan and its operating model. The value of these requirements should be considered in addition to price of vendors' products. The value of product quality, service levels, just in time delivery and technical support are some of the factors which can be considered in the process of vendor's evaluation. Once there is an understanding of the current purchasing situation and an appreciation of what organizations needs to support its business plan and operating model, a search can be done for selecting the most suitable vendors. This way can help the organization to evaluate its vendors and identify the most efficient ones. [1] Vendor selection is the process which review, evaluate and choose the vendors to become a part of organization. It is one of the most important decision making problems, since selecting the suitable vendors significantly reduce the purchasing costs and improves corporate competitiveness. Evaluation methodologies have ranged from simple weighted scoring models to advanced mathematical programming models [5].

Appropriate vendors or suppliers selection is one of the fundamental strategies for achieving the quality of output in any organization, which has a direct influence on the company. The importance of vendor selection has been stated in the literature [6]. Vendor selection decisions are also an important component of production and logistics management in many firms. These decisions are typically complicated for several reasons. First, potential options may require to be assessed on more than one criterion. Dickson [7] identified 23 criteria that have been recognized by purchasing managers in various vendor selection problems. Wind and Robinson [8] concluded that most vendor selection decisions involved multiple criteria. Multi-criteria evaluation has been recognized to be particularly important in manufacturing strategies where criteria such as reliability of delivery and product quality have increased importance [9], [10]. The second complication of vendor selection decisions is that individual vendors may have different performance characteristics based on the different criteria. For example, the vendor who can supply an item for the least per unit price may not have the best delivery, quality or performance in compare with other vendors. The third complication surrounding the vendor selection decision comes from internal policy limitations and externally imposed system constraints placed on the purchasing process. Internal policy constraints exist either implicitly or explicitly in the purchasing process such as the number of vendors, minimum or maximum order quantities, the use of minority vendors, etc. Similarly, suppliers may impose some constraints in the buying process like their own minimum/maximum order quantities based on their production capacity or their willingness to be in contact with a particular firm. These constraints ultimately influence the number of vendors and the order quantities in purchasing function [11].

Partnership with better vendors can help organizations to improve their performance in different aspects. Therefore, for selecting the most suitable vendors, their performance should be measured. In vendor selection problem, a number of methods with different criteria have been developed and examined in SCM. Wind and Robinson [8] proposed a linear weighting method for choosing the best vendors. Gregory used previous works and linked them to a matrix to achieve a new approach to 
solve the problem. During the recent years, some new approaches were proposed by scholars. Buffa and Jakson for measuring the price, quality and delivery, used goal programming (GP) algorithm to solve the problems. Sharma et al. proposed a GP method for measuring price, quality and lead time under budget constraint to vendor selection. Data envelopment analysis, analytic hierarchy process and fuzzy logic are also the methods and approach which have been used in vendor selection problems [11].

Fuzzy logic controller (FLC) is useful when the problem is too complex to be solved with quantitative approaches [4]. During the recent years, a number of researches have been done by applying fuzzy logic controller in order to measure vendors' performance. FLC is also used for assessing suppliers and monitoring supply chain networks [12], [13], [14].

In this paper, service quality, average of late delivery times, price and rate of rejected parts are considered as the main factors which may influence vendors' performance. Parasuraman model is also used to measure vendors' service quality. Data are gathered through a checklist based on the five dimensions of SQ model and vendors' performance is measured through fuzzy logic approach. The output of this approach is a score from twenty which shows the organization's performance based on the mentioned criteria.

\section{Service Quality}

Service quality is a concept that has agitated considerable interest and discussed because of its difficulties in both defining and measuring it with no overall consensus. A number of different "definitions" has been stated to explain service quality concept. One that is commonly used to explain service quality is the extent to which a service meets customers' needs or expectations [15]. Hence, Service quality can be defined as the difference between customer expectations of service and perceived service. If expectations are greater than performance, then perceived quality is less than satisfactory and hence customer dissatisfaction occurs [16].

Numerous service quality literatures have studied conceptualization, measurement, implementation, and management of service quality. The concept of service quality was established after there had been a growing interest in the quality of goods served. Garvin [17] was amongst the first scholars who examined the quality concepts to cover both goods and services. Garvin explained the perceived quality as the subjective perception of quality through indirect measures of quality comparison. Gronross [18] introduced perceived service quality as a result of comparing the real experience with the expectation of a customer before consuming the service. Based on the perceived service quality concept Parasuraman et al. [16] applied premises from other previous studies to form their model of service quality. The ideas included a consumer had difficulty in evaluating service quality rather than goods quality, that a perception of service quality was developed from a comparison of consumer expectation with actual service performance, also quality evaluation involved the evaluation of both the process and outcome of service delivery. Consequently, the conceptual model study of Parasuraman et al. [16] presented five generic dimensions or factors which are as follows: [19]

(1) Tangibles . Physical facilities, equipment and appearance of personnel.

(2) Reliability. Ability to perform the promised service dependably and accurately.

(3) Responsiveness. Willingness to help customers and provide prompt service.

(4) Assurance (Including competence, courtesy, credibility and security). Knowledge and courtesy of employees and their ability to inspire trust and confidence.

(5) Empathy (including access, communication, understanding the customer). Caring and individualized attention that the firm provides to its customers 


\section{Short Description of Fuzzy Inference System Approach}

The "pure fuzzy logic system" is the system where the fuzzy rule base consists of a collection of fuzzy IF-THEN rules, and the fuzzy inference engine uses these fuzzy IF-THEN rules to determine a mapping from fuzzy sets in the input universe of discourse $U \subset R^{n}$ to fuzzy sets in the output universe of discourse $V \subset R$ based on fuzzy logic principles. The fuzzy IF-THEN rules are of the following form:

$$
R^{(l)}: \text { IF } \mathrm{x}_{1} \text { is } F_{1}^{l} \text { and } \ldots \mathrm{x}_{\mathrm{n}} \text { is } F_{n}^{l}
$$

Then y is $G^{l}$

Where $F_{i}^{l}$ and $G^{l}$ are fuzzy sets, $\underline{x}=\left(x_{1}, \ldots, x_{n}\right)^{T} \in U$ and $y \in V$ are input and output linquistic variables, respectively, and $\mathrm{l}=1,2, \ldots$, M. Practice has shown that these fuzzy IF-THEN rules provide a convenient framework to incorporate human experts' knowledge. Each fuzzy IF-THEN rule of Eq. (1) defines a fuzzy set $F_{1}^{l} x \ldots . . x F_{n}^{l} \Rightarrow G^{l}$ in the product space $U \times V$. The most commonly used fuzzy logic principle in the fuzzy inference engine is the so-called sup-star composition, described in detail in [15]. The mini-inference rule and product-inference rule are selected as good from an axiomatic strength point of view, and also because these inferences rules are computationally simple [15]. In our application, we will use the mini-inference type of inferences rules in our adaptive fuzzy system application.

In order to use the "pure fuzzy logic system" in engineering systems where inputs and outputs are realvalued variables, the most straightforward way is to add a fuzzifier to the input and a defuzzifier to the output of the pure fuzzy logic system.

The fuzzy rule base and fuzzy inference engine are the same as those in the pure fuzzy logic system. In the literature, this fuzzy logic system is often called the fuzzy logic controller since it has been mainly used as a controller. It was first proposed by [16], and has been successfully applied to a variety of industrial process and consumer products. A detailed description of this fuzzy logic system can be found in [15].

The Mamdani fuzzy logic system has many attractive features. First, it is suitable for engineering systems because its inputs and outputs are real-valued variables. Second, it provides a natural framework to incorporate fuzzy IF-THEN rules from human experts. Third, there is much freedom in the choices of fuzzifier, fuzzy inference engine, and defuzzifier, so that we may obtain the most suitable fuzzy logic system for a particular problem [15].

\section{Fuzzy Logic in Vendor Performance}

Fuzzy logic is used in performance measurement especially for vendor performance. Kwong et al. [12] applied scoring method with fuzzy expert to supplier assessment in the industry. Mentioned approach has some advantages such as decreasing the errors with implementing the membership functions and evaluation of knowledge with utilizing the fuzzy rules. Lau et al. [13] is applied fuzzy to monitor the supply chain network for the reliable and accuracy reasons. Cahn and Qi [14] proposed an innovative method for performance measurement. They claimed that this method is beneficial for following reasons; first fuzzy helps to reduce the human errors in judgment and decision making and second, defuzzification provide benchmarking for the managers to analyze the effectiveness of the organization. Jain et al. [20] mixed genetic algorithm and FLC to optimize the 
evaluation. Ohdar and Ray [21] applied data collection and genetic algorithm for supplier assessment. Unahabhokha et al. [22] presented fuzzy expert approach to develop forward looking performance measurement for delivery factor in SCM. The approach is developed for managers to establish a systematic way to predict future delivery performance in and identify potential problems in the company. According to the mentioned methods and approaches, in this paper fuzzy logic controller based on the data collection via the questionnaire developed to measure four criteria in vendor selection problems. The result of the research is shown how an organization can measure the performance at the moment with these four criteria. The next section is described the methodology of the work.

\section{Fuzzy Performance Measurement System for Vendor Selection}

FLC design is the major step in the methodology which includes: determining membership function and designing fuzzy rules. Following the process of membership function design and fuzzy rules are defined.

\subsection{Membership Function}

A fuzzy system is a system that works based on imprecise knowledge which is stated by linguistic variables. A membership function (MF) is a part of FLC that provides information which maps the inputted numbers onto the linguistic variables. A MF is basically a curve that defines how each point in the input space is mapped to a membership value (or degree of membership) between 0 and 1. For instance, "high" or "medium" value is referring to MF of the fuzzy set that each point in the curve shows a number between 0 and 1 . In this paper triple membership function is defined with triangular shape with three MFs degree. Triangular membership function shape was chosen because it is most popular in the performance measurement [12], [13], [21]. Range of the membership function depended on the alternatives that were designed for each criterion in the questionnaire.

\subsection{Fuzzy Rules}

The rule base of the proposed FLC was defined in three steps; firstly, total numbers of interactions between the input variables of the FLC were defined. The numbers of rules were established based on the permutation with number of membership function and numbers of criteria. The numbers of factors are six and numbers of membership functions are four. The total amount of rules are $3^{\wedge} 4$ equal to 81 rules. The

rules illustrate all estates between criteria and their relationships. The output of the rules are determined by experts in the company. Finally, rules and membership functions are entered in the MATLAB software and Mamdani type is chosen to evaluate the output of the company. 


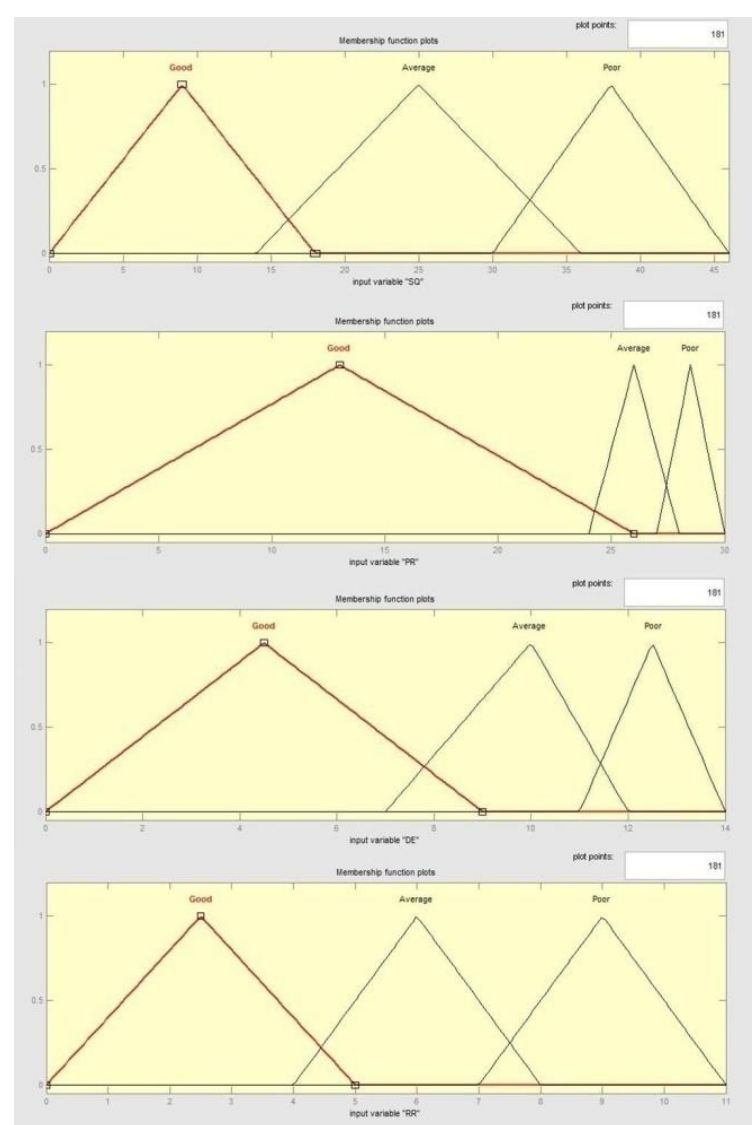

Figure 1. Membership Function in Vendor Selection

\section{Results}

In this paper, twelve P.V.C vendors of one of the Iranian companies in hose production industry are considered and analysed. The Data were gathered through some checklists and some interview with the managers' of the company. The Data are presented in the Table 1.

The results of analysing P.V.C vendors are shown in the Table 2. Based on the method of this paper, high numbers of output illustrate the poor performance and low numbers show high performance. Hence, the lowest number shows the best performance. According to the Table 3, vendor number 6 has the highest level of performance. In contrast, vendors number 9 and 12 have the lowest level in comparison with others.

Table1. Data for Vendor Selection Data

\begin{tabular}{|c|c|c|c|c|}
\hline $\begin{array}{l}\text { Vendor } \\
\text { Number }\end{array}$ & Service Quality & Price & $\begin{array}{c}\text { Lateness } \\
\text { Deliveries }\end{array}$ & Rate of Reject Parts \\
\hline 1 & 25 & 29 & 14 & 3 \\
\hline 2 & 22 & 24 & 6 & 5 \\
\hline 3 & 82 & 30 & 8 & 6 \\
\hline 4 & 20 & 25.5 & 10 & 3 \\
\hline 5 & 57 & 29.5 & 20 & 8 \\
\hline 6 & 10 & 25 & 6 & 3 \\
\hline 7 & 28 & 24.5 & 14 & 4 \\
\hline
\end{tabular}




\begin{tabular}{|c|c|c|c|c|}
\hline 8 & 47 & 28.5 & 12 & 4 \\
\hline 9 & 45 & 27 & 12 & 6 \\
\hline 10 & 39 & 27 & 24 & 4 \\
\hline 11 & 12 & 28.5 & 4 & 5 \\
\hline 12 & 35 & 27.5 & 10 & 8 \\
\hline
\end{tabular}

Table2. Output Performance for twelve P.V.C Vendors

\begin{tabular}{|c|c|c|c|c|c|c|c|}
\hline $\begin{array}{l}\text { Vendor } \\
\text { Number }\end{array}$ & $\begin{array}{c}\text { Output } \\
\text { Performanc } \\
\text { e }\end{array}$ & $\begin{array}{l}\text { Vendor } \\
\text { Number }\end{array}$ & $\begin{array}{c}\text { Output } \\
\text { Performanc } \\
\text { e } \\
\end{array}$ & $\begin{array}{l}\text { Vendor } \\
\text { Number }\end{array}$ & $\begin{array}{c}\text { Output } \\
\text { Performanc } \\
\text { e }\end{array}$ & $\begin{array}{l}\text { Vendor } \\
\text { Number }\end{array}$ & $\begin{array}{c}\text { Output } \\
\text { Performanc } \\
\text { e }\end{array}$ \\
\hline 1 & 5 & 4 & 5.54 & 7 & 5 & 10 & 5 \\
\hline 2 & 5.96 & 5 & 5 & 8 & 5 & 11 & 5.89 \\
\hline 3 & 5 & 6 & 2.5 & 9 & 8.5 & 12 & 7.78 \\
\hline
\end{tabular}

\section{Conclusions}

One of the success keys for managers is selecting the most appropriate vendors based on their performances. It has been proved that vendor selection may influence organization's performance, product quality and services directly. Hence, this question is remained that, how indicators can be monitored in the organization? Which vendor is better in comparison with others? To answer the mentioned questions fuzzy logic controller is applied as a robust method in vendor selection problem.

In this paper, four effective factors including service quality, price, lateness deliveries and rate $\mathrm{f}$ reject parts were considered in the performance measurement. Then, FLC approach, appropriate membership functions and fuzzy rules were used and defined in the MATLAB software. Finally, a framework for measuring performance was obtained that change the linguistic terms to quantitative variables.

\section{References}

[1] Hugos, M. "Essentials of Supply Chain Management", New Jersey: John Wiley, 2003.

[2] Chopra, S. and Meindel, P. "Supply chain management: strategy, planning and operations", Prentice Hall, 2001.

[3] Mentzer, J.K. "Fundamentals of supply chain management: twelve drivers of competitive advantage", Sage Publication, 2004.

[4] Kumar, M., Vrat, P., and Shankar, R. " A fuzzy goal programming approach for vendor selection problem in a supply chain”, Computers and Industrial Engineering, Vol. 46, pp. 69-85, 2004.

[5] Talluri, S., Narasimhan, R., and Nair, A., "Vendor performance with supply risk: a chance-constrained DEA approach", International Journal of Production Economics, Vol. 100, No. 2, pp. 212-222, 2006.

[6] Weber, C.A., Current, J.R. and Benton, W.C., "Vendor selection criteria and methods", European Journal of Operational Research, Vol. 50 No. 1, pp. 2-18, 1991.

[7] Dickson, G.W., "An analysis of vendor selection systems and decisions", Journal of Purchasing, Vol. 2, No. 1, pp. 5-17, 1966.

[8] Wind, Y. and Robinson, P.J., "The determinants of vendor selection: the evaluation function approach", Journal of Purchasing and Materials Management, August, pp. 29-41, 1968.

[9] Chapman, S.N., "Just-in-time supplier inventory: An empirical implementation model", International Journal of Production Research, Vol. 27, No. 12, pp. 1993-2007, 1989.

[10] Chapman, S.N., and Carter, P.L. "Supplier/customer inventory relationships under just-in-time", Decision Sciences, Vol. 21, pp. 35-51, 1990.

[11] Weber, C.A., Current, J. \& Desai, A., "An optimization approach to determining the number of vendors to employ", Supply Chain Management: An International Journal, Vol. 5, No. 2, pp. 90-98, 2000. 
[12] Kwong, C.k., Lp, W.H., and Chan, J.W.K. "Combining scoring method and fuzzy expert", Integrated Manufacturing Systems, Vol. 13, No. 7, pp. 512-519, 2002.

[13] Lau, H.C.W., Pang, W.K., and Wong, C.W.Y. "Methodology for monitoring supply chain performance: a fuzzy logic approach" Logistics Information Management, Vol. 15, No.4, pp.271-280, 2002.

[14] Chan, F.T.S., and Qi, H.J. "An innovative performance measurement method for supply chain management", Supply Chain Management: An International Journal, Vol.8, No.3, pp.209-223, 2003.

[15] Guimaraes, A.C.F., and Lapa. C.M.F. "Fuzzy Inference to risk Assessment on Nuclear Engineering Systems", Applied Soft Computing, Vol. 7, pp.17-28, 2007.

[16] Parasuraman, A., Zeithaml, V. A., and Berry, L. L. "A conceptual model of service quality and its implications for future research", Journal of Marketing, Vol. 49, pp.41-50, 1985.

[17] Garvin, D. A., Managing Quality: The Strategic and Competitive Edge. 1st Edition, New York: The Free Press, 1988.

[18] Gronroos, C., Quality comes to service. In E. E. Scheuing and W. F. Christopher (Eds.). The Service Quality Handbook (pp. 17-24). New York, USA: AMACOM, 1993.

[19] Kang G. D., James J., Alexandris K., "Measuring of internal service quality" , Managing service quality, Vol 12 No. 5, pp. 278-291, 2002.

[20] Jain, V., Tiwari, M.K., and Chan, F.T.S. "Evaluation of the supplier performance using an evolutionary fuzzy-based approach" Journal of Manufacturing Technology Management, Vol.15, No.8, pp.735-744, 2004.

[21] Ohdar, R., and Ray, P.K. "Performance measurement and evaluation of suppliers in supply chain: an evolutionary approach", Journal of Manufacturing Technology Management, Vol.15, No.8, pp.723-734, 2004.

[22] Unahabhokha, C., Platts, K., and Hua Tan, K. "Predictive performance measurement system: A fuzzy expert system approach", Benchmarking: An International Journal, Vol.14, No.1, pp.77-89, 2007. 